ISSN: 2162-3104 Print/ ISSN: 2166-3750 Online

Volume 8, Issue 2 (2018), pp. 1173-1197

(C) Journal of International Students

http://jistudents.org/

doi: 10.5281/zenodo.1250419

\title{
Chinese International Students' Experiences in American Higher Education Institutes: A Critical Review of the Literature
}

Qianqian Zhang-Wu

Boston College, USA

\begin{abstract}
Using database searches in ProQuest Sociology, Education Research Complete, ERIC, and Google Scholar, this landscape literature review provides research synthesis and analysis on research designs, underlying assumptions and findings of 21 recent peer-reviewed scholarly articles focusing on Chinese international students' experiences in American higher education institutes. Patterns observed across studies regarding colorblind racism are presented in the discussion. Towards the end, this review closes with implications and directions for future research.
\end{abstract}

Keywords: American higher education; Chinese international students; colorblind racism

With the skyrocketing trend of globalization, more and more students choose to go abroad to further their education. According to Open Doors Data from the Institute of International Education (IIE, 2016a), the total number of international students pursuing undergraduate degrees overseas in the year of 2015 to 2016 has peaked at 427,313, witnessing a 7.1\% increase from the previous year. With an upward trend of $8.1 \%$ compared with the year of 2014 to 2015, China remains to be the top country of origin for international students, exporting $31.5 \%(328,547)$ of the 2016 world's total, 
followed by India (15.9\%), Saudi Arabia (5.9\%) and South Korea (5.8\%) (IIE, 2016b).

International students have some fundamental differences from immigrants. Firstly, unlike immigrants who are mostly citizens and permanent residents of the host country, international students remain citizenship of their home countries while holding short-term student visas issued by the host country (usually expire once academic programs end). Secondly, dissimilar to immigrants who are likely to struggle financially (Center for Immigrant Studies, 2011), international students tend to enjoy much higher socioeconomic status (SES). In fact, $81.2 \%$ of international students perusing undergraduate degrees overseas have 'personal/family' as the primary source of funding (IIE, 2016c). This alone has contributed $\$ 32.8$ billion profits and created over 4 million job opportunities in the academic year of 2015 to 2016 to the United States, the world's largest hosting country for international students (Association of International Educators, 2016). Last but not least, different from immigrants who leave their home country in the hope of pursuing permanent residence in the hosting country, most international students travel overseas only for educational purposes and tend to return to their homeland within a few years. Their overseas educational experience serves as "a strategy for contributing to the family's cultural, economic, and social capital, which may be directly convertible into monetary gains" (Park, 2016, p. 238). In other words, rather than being eager to leave their home countries for better life in the host country, as are most immigrants, a considerable number of international students pursue overseas studies to maintain or increase social capitals and SES in their home countries (Ball, 1993, 2003; Brown, 1990, 1995).

Despite such distinct differences, not only are international students poorly distinguished from immigrants, but also they are often grouped under the category of immigrants in many scholarly studies (e.g., Chang, Park, Lin, Poon, \& Nakanishi, 2007; Kagawa, Hune, \& Park, 2011; Lim, 2015; Park, Lin, Poon, \& Chang, 2008). For example, in Beyond Myths: The Growth and Diversity of Asian American College Freshmen 1971-2005, a well-known, award-winning research project conducted by Chang and colleagues (2007) featuring "the largest compilation and analysis of data on Asian American college students" (Diverse Issues in Higher Education, 2008, p. 5), data from college-level international students of Asian origins and Asian American immigrants were not well distinguished, but rather mixed together to represent Asian American college students. While 
acknowledging this problem in their description of method section by stating that "[a]lthough Asian international students are included in the Asian/Asian American sample, we use the term 'Asian American' in the report to describe the group" (Chang et al., 2007, p. 5), Chang and colleagues did not list their inclusion of Asian international students into Asian American immigrant category as one of their research limitations. Despite the humongous sample size of this quantitative study, blending these two drastically different populations under the same umbrella term of Asian American college students has certainly skewed the accuracy of its research findings, particularly concerning their reported percentages of 'low-SES Asian American freshmen' (international students tend to have much higher SES than immigrants) and 'Asian American freshmen intending to get a job to pay for college tuitions' (it is illegal for international students to work off-campus).

Compared with immigrants, international student populations have received much less research attention. Even when studied, they are often mistakenly blended into the category of immigrants (e.g., Chang, Park, Lin, Poon, \& Nakanishi, 2007; Kagawa, Hune, \& Park, 2011; Lim, 2015; Park, Lin, Poon, \& Chang, 2008). Given the uniqueness of this population and its fast-growing trend in recent years, it is important to systematically investigate the experiences of international students. In this review, I would like to focus specifically on Chinese international students in the United States. I limited my attention to Chinese international students, as they have been representing the largest number of international students worldwide since 2000 (IIE, 2016b). Similarly, I selected the U.S. as the country of interest due to its celebrity of being the most popular overseas study destination for international students (Mazzarol \& Soutar, 2002; Park, 2016). The purpose of this literature review is to explore answers to the following questions: 1) What does research say about Chinese international students' experiences in American universities? 2) What patterns and implications can be found in analyzing existing literature on this topic? In the remainder of the article, I discuss methodological approach of this review, present research synthesis based on the organizational framework, conduct discussions on patterns observed regarding colorblind racism, and close with implications for future research. 


\section{RESEARCH METHOD}

In order to answer the aforementioned research questions, I resorted to electronic databases including ProQuest Sociology, Education Research Complete, ERIC, and Google Scholar in search of the literature. I paired up the search terms Chinese international student, Chinese transnational student, Chinese student, or student* from China, with higher education, university, or college, in combination with America, United States, or US. This has initially yielded 164 results. I also conducted searches using the same search terms within several higher education journals including Journal of Studies in International Education, Comparative and International Higher Education, Journal of Research in International Education, and Journal of International Students and gained an additional 8 studies.

The pool of articles yielded were examined based on the following criteria: 1) to ensure the quality of the review, only peer-reviewed empirical articles written in English language and published in scholarly journals were included; 2) a time limiter of articles published after 2000 was further applied, because China has witnessed significant economic growth since the beginning of the 21st century (The World Bank, 2016), and has remained the leading international student exporting country since 2000 (IIE, 2009). Articles failing to meet the inclusion criteria as well as duplicated search findings were excluded from the pool. Moreover, after reviewing the contents of the remaining articles, I further eliminated articles which happened to contain some search terms and meet the search criteria, yet addressed irrelevant populations (e.g., Chinese American immigrants, K-12 students), or focused on international students studying in countries other than the U.S. (e.g., China, Canada, UK, Singapore, Australia, Hungary etc.). Eventually, I was able to finalize a pool of 21 studies.

\section{Organizational Framework}

In framing the literature review, I categorized the final pool of articles into 3 groups based on their research focuses. Table 1 presents a summary of the organization framework, and also provides a brief summary of the methodology used. As several articles (e.g., Spencer-Rodgers \& McGovern, 2002; Wang, 2009; Yang, Wu, Zhu, Brian, \& Southwell, 2004; Yeh \& Inose, 2003) simultaneously addressed more than one research focus, I placed them repeatedly under corresponding categories. 
Table 1. Organizational Framework Based on Research Focuses

Focus 1: Language Barriers

\begin{tabular}{ll}
\hline Study & Methodology \\
\hline Cheng \& Erben (2011) & Mixed-methods approach \\
Jarratt, Losh, \& Puente (2006) & Mixed-methods approach \\
Jiang (2014) & Qualitative (case study) \\
$\begin{array}{l}\text { M. Wang (2016) } \\
\text { Spencer-Rodgers \& McGovern } \\
\text { (2002) }\end{array}$ & Qualitative (case study) \\
Spencer-Rodgers (2001) & \\
W. Wang (2009) & Quantitative (survey analysis) \\
Xue (2013) & Quantitative (survey analysis) \\
Yeh \& Inose (2003) & Qualitative (phenomenological approach) \\
\hline
\end{tabular}

Focus 2: Acculturation

\begin{tabular}{ll}
\hline Study & Methodology \\
\hline Batterton \& Horner (2016) & Mixed-methods approach \\
Cheng \& Erben (2011) & Mixed-methods approach \\
Hanassab (2006) & Quantitative (survey analysis) \\
K. Wang et al. (2012) & Quantitative (survey analysis) \\
Lee \& Rice (2007) & Mixed-methods approach \\
Pan, Wong, \& Ye (2013) & Quantitative (survey analysis) \\
W. Wang (2009) & Quantitative (survey analysis) \\
Yang et al. (2004) & Quantitative (survey analysis) \\
Ye (2006a) & Quantitative (survey analysis) \\
Yeh \& Inose (2003) & Quantitative (survey analysis) \\
\hline
\end{tabular}

Focus 3: Intercultural Communication

\begin{tabular}{ll}
\hline Study & Methodology \\
\hline Fraiberg \& Cui (2016) & Qualitative (ethnographic approach) \\
Li \& Chen (2014) & Quantitative (survey analysis) \\
Lin (2006) & Qualitative (observations, interviews, \\
& document analysis) \\
M. Wang (2016) & Qualitative (case study) \\
Yang et al. (2004) & Quantitative (survey analysis) \\
Ye (2006a) & Quantitative (survey analysis) \\
Ye (2006b) & Quantitative (survey analysis) \\
\hline
\end{tabular}




\section{RESULTS}

\section{Research Focus 1: Language Barriers}

\section{Research Design}

There are 9 studies in this category, which pay attention to the various language barriers that international students face in their transnational experience. As summarized in Table 1, this group of study consists of 4 quantitative studies applying survey methods and involving data analytic approaches such as analysis of covariance (ANCOVA) and multivariate analysis of variance (MANOVA) (Spencer-Rodgers \& McGovern, 2002; Spencer-Rodgers, 2001; W. Wang, 2009; Yeh \& Inose, 2003), 3 qualitative studies using a combination of research methods such as interviews and participatory observations (Jiang, 2014; M. Wang, 2016; Xue, 2013), and 2 sequential mixed-methods study integrating quantitative survey methods with qualitative interviews (Cheng \& Erben, 2011) and written journal analysis (Jarratt, Losh, \& Puente, 2006).

While a seemingly balanced number of quantitative and nonquantitative studies are identified in this category, there is an unbalanced trend as all 5 non-quantitative studies provided justifications for their methodology choice, while none of the quantitative studies did so. To be specific, contrasting to the quantitative studies which directly presented participants, recruitment procedure, measuring instruments and analytic plans before discussing the results in their methods section, the nonquantitative studies went to great length in justifying their rationales to conduct a case study (M. Wang, 2016), adopt a qualitative phenomenological approach (Xue, 2013), apply interview methods (Jiang, 2014), and choose a sequential mixed model (Cheng \& Erben, 2011). Some studies (Jiang, 2014; Xue, 2013) further explicitly mentioned the issue of researcher bias, implying that subjectivity exists as an internal limitation due to the nature of qualitative research.

The contrasting ways that quantitative and non-quantitative researchers framed their studies has pointed to the greater issue of subjectivity and research bias. It seems that these quantitative studies present themselves as comparatively more objective and unbiased, given their 'confidence' of directly presenting methodology without much clarification. In contrast, non-quantitative studies in this group appears to be much more cautious, providing justifications for methodology choice and 
acknowledging the corresponding potential limitation of subjectivity. Due to these reasons, the non-qualitative studies have been portrayed as if they were inferior, subjective, and less legitimate.

Nevertheless, subjectivity is inevitable in all research, quantitative or non-quantitative alike. As Ramazanoglu (1992) has wisely put it, "it is more logical to accept our subjectivity, our emotions and our socially grounded positions than to assume some of us can rise above them" (p. 211). The choice of articles to include in the literature review, the decision in recruiting participants, the analysis and interpretation of data and the conclusion drawn all involves subjectivity (Westmarland, 2001). Therefore, while practices such as member checking are always desirable in reducing researcher bias (Creswell \& Miller, 2000; Krefting, 1991), it seems unnecessary for non-quantitative research to emphasize the issue of subjectivity as its inferiority.

\section{Underlying Assumptions}

Most studies in this group, regardless of their methodology, are with the underlying assumption that Chinese international students are linguistically incompetent in the host country (e.g., Cheng \& Erben, 2012; Jiang, 2014; M. Wang, 2016; W. Wang, 2009; Xue, 2013). Prior to the research being conducted and results being analyzed, many studies have already betrayed a negative position toward Chinese international students' language experiences by using terms such as language barrier (M. Wang, 2016), incompetent (Jiang, 2014), language difficulties (Yeh \& Inose, 2003), deficiency in English (Xue, 2013) in their introductions. Such language barriers are said to be, to a great extent, caused by the different Chinese and American educational cultures and practices (Cheng \& Erben, 2012; Jiang, 2014; M. Wang, 2016; W. Wang, 2009; Xue, 2013). While American education emphasizes discussion and collaboration, paying more attention to English listening and speaking, Chinese educational policies and practices focus more on learning English grammar, reading and writing. Thus, despite their high performance on gatekeeping English language proficiency exams such as the Test of English as a Foreign Language (TOEFL) and International English Language Testing System (IELTS), Chinese international students tend to be severely under-prepared when they are in authentic English-speaking situations (M. Wang, 2016; Xue, 2013).

While agreeing that when they pursue overseas studies in the US, Chinese international students are non-native English speakers and could 
have some linguistic adjustment challenges particularly regarding spoken English (e.g., fluency, accent), such an underlying assumption appears problematic mainly for two reasons. On the one hand, it betrays a deficit perspective toward Chinese international students, viewing them as linguistically incapable and less competent without acknowledging their bilingual and biliterate talents in the U.S., a culturally and linguistically diverse country. Such an assumption ignores the value of their home language, masks their high literacy level in Chinese, denies the current status of World Englishes and English as a lingua franca (Jenkins, 2006) and reinforces the so-called native-speaker superiority fallacy (Canagarajah, 1999).

On the other hand, assuming the language experiences of international students as negative even before conducting research could overlook the diverse experiences that individuals may have, masking possible successful stories of high-English-proficiency international students. For example, while the majority of Chinese international students studying in American universities came directly after graduating from high schools in China, some have received high school or community college education in the US before entering 4-year universities. These groups of students are more exposed to the English-speaking environment and are thus likely to have higher language proficiency. Regarding all Chinese international students as a homogeneous group could potentially bring bias into research design, increasing the possibility of asking misleading interview or survey questions which focus mainly on the negative side of international students' transnational language experiences. For example, in Cheng and Erben's (2012) study, a modified questionnaire which was originally designed to examine students' anxiety in foreign language classroom has been applied to gauge Chinese international students' language experiences in America. Although the researchers have made some context-related modifications (e.g., changing "in language class" from the original questionnaire to "in classes" to fit college international students' situation), the overall negative wording of all questions were not changed. To be specific, all the 33 questionnaire items were reverse-worded, presenting negative statements such as "I tremble when I know that I'm going to be called on in classes" (Cheng \& Erben, 2012, p. 483) rather than more neutral or positive prompts such as "I feel comfortable when speaking in classes." Presenting Likert-Scale statements with an excessive focus on the incompetent sides of international students' language usage could 
mislead the participants in retrieving their purely negative memories, which could eventually skew the analysis of their true experiences.

\section{Findings}

Self-reported English language proficiency has been found to be related to Chinese international students' communication effectiveness (Jiang, 2014; M. Wang, 2016; Xue, 2013), academic performance (Xue, 2013), psychological well-being (Yeh \& Inose, 2003) and transnational adjustment ability (Cheng \& Erben, 2011; W. Wang, 2009; Yeh \& Inose, 2003) in the US. For instance, most of Xue's (2013) participants reported that their unsatisfactory English proficiency has hindered their participation during group work; the author concluded with pedagogical inferences for English-as-a-foreign-language (EFL) instruction in China. Similarly, Jiang's (2014) case study of 4 Chinese graduate teaching assistants (TAs) showed that all participants self-perceived as "linguistically inadequate" (p. 206), and thus had difficulty fulfilling TAing tasks. Jiang (2014) concluded that English proficiency and content knowledge played a more important role in determining successful course instruction than cultural differences between home and host countries, and discussed implications for college TA training programs. From a completely different perspective focusing on American students' perceptions of international students rather than international students' narratives and self-reflections, it has been found that poor English proficiency still remains to be the most mentioned negative descriptor of international students (Spencer-Rodgers, 2001), and such a negative perception is likely to result in unfavorable stereotypes against them (Spencer-Rodgers \& McGovern, 2002).

Findings above from the angles of international students and their American counterparts have implied that international students face twofolded challenges upon their arrival at American higher education institutes: to get used to an authentic English-speaking environment on the one hand, and to overcome presumed linguistic incompetence by native speakers on the other. Several ways have been identified to reduce their language anxiety. Cheng and Erben (2011) found that longer stay in the host country and enrollment in art-related majors could lower international students' anxiety toward English. According to Xue (2013), increased group work participation with native speakers could also increase international students' English proficiency, and thus reduce language anxiety. Lastly but not least, W. Wang (2009) reported that Chinese international students' high self- 
confidence in English correlated with low English language anxiety, implying that boosting self-confidence could help increase their language fluency and communicative competence.

\section{Research Focus 2: Acculturation}

\section{Research Design}

The research in this category focuses on international students' degrees of acculturation and acculturative stress in the host country. Every one of the 10 studies adopts at least some survey elements, with 7 pure quantitative studies using survey methods (e.g., Hanassab, 2006; Pan, Wong, \& Ye, 2013; Yang, Wu, Zhu, Brian, \& Southwell, 2004; Ye, 2006a), and 3 sequential mixed-methods studies with qualitative interviews following quantitative survey analysis (Batterton \& Horner, 2016; Cheng \& Erben, 2011; Lee \& Rice, 2007).

The frequent usage of a survey approach in this group of studies may relate to the advantage of questionnaires in simultaneously accessing multiple participants, and the decent number of previously designed questionnaires available in examining acculturation issues. On the one hand, quantitative survey methods feature administering close-ended questions to a representative sample of participants, the answers of which could be later coded as variables and analyzed statistically to infer the conditions of a larger population, which allow efficiently examination of a great number of participants at once (Westmarland, 2001). In their investigation of international students' acculturation, Hanassab (2006), Lee and Rice (2007), $\mathrm{K}$. Wang, Heppner, Fu, Zhao, Li, and Chuang (2012), and Yeh and Inose (2003) all recruited over 350 participants and investigated their individual acculturative experiences through the administration of questionnaires. Moreover, thanks to its advantage of accessing a wide range of participants, all 3 mixed-methods studies (Batterton \& Horner, 2016; Cheng \& Erben, 2011; Lee \& Rice, 2007) adopted a survey approach so as to recruit later interview participants.

On the other hand, there are abundant ready-made questionnaires designed by previous research on the topic of acculturation, which are easily applicable and adaptable. Two particularly popular pre-designed questionnaires widely cited and adopted by research on acculturation are the Acculturative Stress Scale for International Students (ASSIS, Sandhu \& Asrabadi, 1994, adopted in K. Wang et al., 2012; Yeh \& Inose, 2003) and the Acculturation Index (AI, Ward \& Rana-Deuba, 1999, adopted in W. 
Wang, 2009). While integrating readily-available, previously-published questionnaires as an instrument tool has the advantages of simplifying research design process and increasing the reliability of psychometric information (i.e., Cronbach Alphas have been tested across studies adopting this scale), there are still some limitations. Firstly, with regards to the aforementioned AI (Ward \& Rana-Deuba, 1999) for instance, despite its popularity in the field, it was originally created based on John Berry's (1997) acculturation theory which focused on the adaptation and acculturation of immigrants. Given the remarkable differences between international students and immigrants, the appropriateness of using immigration-theory-informed AI in gauging Chinese international students' acculturation is under question. Detailed discussions will be presented in the following section about underlying assumption and theoretical framework. Moreover, when it comes to ASSIS (Sandhu \& Asrabadi, 1994), even though this widely-cited work was created especially for international students, given its obsolete publishing date and the significant changes of the international student demographics over the years, it seems improper to integrate it directly with no adjustments into more recent research.

\section{Underlying Assumptions and Theoretical Framework}

While the group of studies all focus on Chinese international students' acculturation, the vast majority of them (Batterton \& Horner, 2016; K. Wang et al., 2012; W. Wang, 2009; Yang et al., 2004; Ye, 2006a; Yeh \& Inose, 2003) have drawn upon Berry's (1997) or Phinney's (1996) framework as their guiding theory, which aims to address the acculturation process of immigrants rather than international students. Although Cheng and Erben (2011) did not refer to Berry or Phinney's classic piece, they frequently cited García's (2001) work focusing on immigrant children in K12 education, which also deviates from their population of interestcollege-level Chinese international students. Among the rest 3 studies which did not adopt an immigration-related framework, Hanassab (2006) and Lee and Rice (2007) drew on specific psychological theories exploring international students' experiences with stereotype and discrimination during acculturation, while Pan, Wong, and Ye (2013) went beyond immigration literature and resorted to migration theories in order to develop a scale which measures the personal growth aspects of Chinese international students after their migration into the host country. However, in spite of their breakthrough in going beyond an immigrant-oriented framework in 
research design, Pan and colleagues (2013) recruited "a sample of 400 mainland Chinese students studying in Hong Kong" (p. 1639) as initial survey participants to validate the scale before they finally re-administered the questionnaire to Chinese international students studying in western contexts. Since Hong Kong is a special administrative region of China rather than a different country, referring to mainland Chinese students studying in Hong Kong as international students and depending on them as a scale validation group is certainly inaccurate, which undermines the overall quality of the research.

The underlying assumption of adopting an immigrant-oriented framework seems to be that international students are the same with immigrants. While the two populations indeed share some similarities especially with regards to their transnational experiences as well as experiences exposing to two distinct cultures, they are fundamentally different in many ways. As mentioned earlier, dissimilar to immigrants, most international students do not plan to stay in the host country in the long run, but rather use overseas educational experience to enhance their social capitals in the home country (Park, 2016), making their acculturation into the host country less mandatory. Moreover, international students are likely to have much higher SES (Center for Immigrant Studies, 2011; Institute of International Education, 2016c), making them less motivated to assimilate into the host country in pursuit of a better life, as many immigrants do.

Purely using an immigrant-oriented theory in examining international students' acculturation can be problematic. For example, in immigrant-oriented theories (e.g., Berry, 1997; Phinney 1990), aspects such as language practice, area of residence and political participation are often key components to be gauged in understanding participants' degrees of acculturation. Nevertheless, these aspects seem less relevant when it comes to international students. Firstly, regarding language usage, international college students' daily English usage is required in order to participate in academic programs, which fails to reflect their personal preference of English (the language of host country) over Chinese (that of home country). Similarly, location of residence also falls short in indicating international students' degrees of acculturation, as many universities require students to live on campus during the first several years. Lastly, political participation is irrelevant to international students: since they are not lawful permanent residents or citizens of the host country, they are hardly endowed any political rights. Therefore, instead of designing research, choosing 
instruments, and conducting analysis following traditional immigration theories, it appears more appropriate to acknowledge international students' uniqueness, evaluate their acculturative needs, and conduct research based on international student-targeted theoretical frameworks.

\section{Findings}

Drawing upon Berry's (1997) framework, K. Wang et al. (2012) investigated Chinese international students' acculturative patterns, and categorized participants into 4 groups, namely consistently distressed, relieved, culture-shocked, and well-adjusted. Sharing the same theoretical framework, W. Wong (2009) focused on acculturation strategies and crosscultural adjustment, and found that for Chinese international students, assimilation is the best strategy, followed by integration and separation. Also guided by an immigrant-oriented framework, Cheng and Erben (2011) concluded that those Chinese international students who are self-evaluated as more acculturated tended to have less language anxiety.

Among the 4 studies focusing on the cross-cultural experiences of international students from various places (Chinese international students included) who are studying in the U.S., Batterton and Horner (2016) drew upon Phinney's (1996) framework to study the ethnic and national identity development among international college students. The authors found that identity development was complicated; international students' identities shifted from discoverers to ambassadors and negotiators depending on different contexts (Batterton \& Horner, 2016). From a different angle, Lee and Rice (2007) focused on discrimination experienced during international students' acculturation. As the title Welcome to America? indicated, international students from different cultural and linguistic backgrounds experienced different degrees of discrimination, with those who were nonwhite suffering more discrimination. Similarly, Hanassab (2006) and Yeh and Inose (2003) discovered that compared with international students from Europe, those who were from Asia experienced more acculturative stress in all aspects investigated.

Rather than paying attention to the negative aspects of acculturation such as discrimination and acculturative stress, Pan, Wong, and Ye (2013) paid special attention to one positive area-Chinese international students' psychological growth after arrival into the host country, and investigated post-migration growth in both intrapersonal and interpersonal dimensions. However, as discussed in earlier section, their study was prone to have weak 
validity and reliability due to problematic sample choice during scale development and validation.

Interested in the relationship between acculturation and media use, Yang et al. (2004) identified that Chinese international students' motives for media use has positive correlations with both their acculturation needs and the frequency of their American media usage. Also focusing on media usage, Ye (2006a) examined the relationship between acculturative stress and online social group use, and concluded that the more online emotional support Chinese international students received, the less acculturative stress they would experience.

\section{Research Focus 3: Social Networking}

\section{Research Design}

There are 7 articles focusing on Chinese international students' social networking in the U.S., with 4 applying quantitative survey methods (Li \& Chen, 2014; Yang et al., 2004; Ye, 2006a; Ye, 2006b) and 3 qualitative studies adopting a variety of approaches including ethnography (Fraiberg \& Cui, 2016), case study (M. Wang, 2016), and a combination of observations, interviews and document analysis (Lin, 2006).

According to the names and biography information of the authors, it is clear that each of the 7 studies involves at least 1 author of Chinese origin. With Chinese international students as focal research participants, all the three qualitative studies (Fraiberg \& Cui, 2016; Lin, 2006; M. Wang, 2016) have utilized both Chinese and English languages during the studies, while all the quantitative studies (Li \& Chen, 2014; Yang et al., 2004; Ye, 2006a; Ye, 2006b) adopted only English throughout contacts with participants. To be specific, in M. Wang's (2016) case study exploring the influence of Chinese cultural influence on international students' social networking in American higher education institutes, participants were given the choice of being interviewed in English or Chinese. All the 3 international students preferred to communicate with the researcher in Mandarin Chinese. Those interviews were recorded, transcribed, and sent through emails to each participants in order to clarify any inaccurate information, before finally translated by the researcher (native in Mandarin, advanced in English) into English. Such constant member checking serves as a good way to boost research rigor (Creswell \& Miller, 2000; Krefting, 1991). Similarly, in Lin (2006), Chinese was adopted during focused group interviews, while in 
Fraiberg and Cui (2016), students' online instant message chatting in Chinese was recorded, translated and analyzed.

On the contrary, although the 4 quantitative studies aimed to investigate Chinese international students' social networking experiences, surveys were only provided in English with no option of selecting Chinese version as an alternative. Aforementioned research on Chinese international students' language proficiency has found that many students reported having English language anxiety or lacking confidence in daily English practices (e.g., Cheng \& Erben, 2011; Xue, 2013). It seems that allowing a Chinese version of the questionnaire as an option might potentially reduce such anxiety and make participants feel more relaxed. Additionally, for students with lower English proficiency in particular, a survey in Chinese could also help avoid unnecessarily misunderstanding due to language barriers. Moreover, even for students with high English proficiency, first language usage was still preferred during research (M. Wang, 2016). As participants claimed to be "more comfortable sharing their lived experience in their first language" (M. Wang, 2016, p. 615), adding a Chinese version as an alternative choice may also increase potential research subjects' willingness of participation, considering the relatively low response rates toward English surveys. For instance, in Li and Chen's (2014) study, despite cash incentives, less than one third of Chinese international students responded to the surveys in English.

\section{Underlying Assumption}

In order to examine the social networking among Chinese international students, a group of studies (Fraiberg \& Cui, 2016; Li \& Chen, 2014; Yang et al., 2014; Ye, 2006a; Ye, 2006b) have been conducted focusing on online social media (e.g., Facebook, Renren, QQ) usage. While investigation and comparison of international students' social media usage patterns could shed lights on their degrees of connectedness with home and host countries, some research was likely to be carried out based on the underlying assumption that social media usage was decontextualized, with no variation when locations changed.

Such an underlying assumption equating transnational social networking media usage with that of one single country could be harmful. This is because the same form of media may have different characteristics in different sociocultural contexts, ignoring which could compromise the overall quality of the research. For instance, in their comparative research of 
Chinese international students' usage of two online social networking sites Facebook and Renren (a Chinese social media website which functions similarly to Facebook), Li and Chen (2014) investigated the intensity and purpose of participants' social media usage. They found that while Facebook use could be more helpful for international students to establish connections with the host country (the U.S.), Renren use was more beneficial to maintain closeness with the home country (China). While the study itself was well-designed, and conducted and analyzed in an appropriate manner, it failed to take consideration of contextualized factors and acknowledge right at the beginning of the article that Facebook connection and usage was actually banned by Chinese government since 2009 (MacDonald, 2009). Due to this restriction, Renren became a dominant social media platform, or the 'Chinese version of Facebook' for international students to stay connected with friends and family in China, making Li and Chen's (2014) later analysis and finding that 'compared with Facebook, Renren was more related to home country connectedness' seems obvious and even redundant. In the same way, as Facebook was banned in China yet popular in America, it naturally served as a major way for international students to socialize with acquaintances in the U.S., also making it evident that Facebook functioned as a channel to connect participants with the host country. Without contextualizing the social media platforms before designing research, the significance of this study has been greatly weakened.

Similarly, in their examination of Chinese international students' TV and internet usage in the U.S., Yang and colleagues (2004) found through Factor Analysis of survey data that while TV watching was more closely related to participants' acculturative motives, internet usage was "apparently largely a way 'to find what's going on in China' rather than 'to find what's going on in America"” (p. 91). Despite their transparent research design, given the fact that the vast majority of TV programs available in the U.S. were about the host country with little information on local news of China, it was obvious that participants were more likely to watch TV in order to explore current events of the host than the home country. By the same token, as TV failed to provide adequate information of China, it was highly predictable that participants would resort to internet to connect with family and friends in China and stay updated with Chinese news, which again made the research findings seemingly evident. In sum, regardless of its novel research focus, without situating the forms of social media under 
investigation into a cross-cultural context, the value of the study is somewhat compromised.

\section{Findings}

Examining Chinese international students' social networks through online platforms, Li and Chen (2014) conducted an online survey to compare participants' usage of home country social media website Renren and host country site Facebook, and found that while Facebook usage predicted connectedness with American society, Renren was related to the maintenance of ethnic relationship. The authors concluded that online social networking services presented platforms for Chinese international students to grow their social capital, both in and outside their home country. Also interested in Chinese international students' online social media use and its influences, Fraiberg and Cui (2016) adopted an ethnographic approach to investigate participants' interactions using a Chinese online group chat service, QQ. They paid attention to how literacy activity (i.e., online group messaging via QQ) in participants' first language could potentially inform that in their second language, and concluded that such online social media practice of guanxi wang (interpersonal networks) would assist international students' transition into a new academic environment. From a slightly different perspective, Yang at al. (2004) focused not only on social networking, but also the relationship between acculturative motive and media use. Through survey analysis of 84 Chinese international students studying in the U.S., Yang and colleagues (2004) confirmed their earlier hypothesis that participants' intensity of US-based social media usage would increase when they have stronger acculturative motives into American society.

Going beyond the pure focus on online social media, Ye (2006a; 2006b) compared the differences between social support participants received from traditional interpersonal social networks and that from online platforms. According to survey results from analysis of covariance, the researcher found a negative relationship between perceived satisfaction from interpersonal and online support networks (Ye, 2006a). Moreover, while both types of social support were beneficial in helping participants to cope with social challenges in the host country, online ethnic support networks were particularly welcomed by newly arrived international students. Also paying attention to the support international students received through social networks, Lin's (2006) research illustrated how a Chinese student 
organization offered social support to assist participants in conquering culture shock and increasing cross-cultural competency, and how connections with organization members from the same culture could provide help in intercultural adjustment. Through a 7-month case study, M. Wang (2016) adopted an insider-outsider positionality and analyzed the experience of 3 Chinese international students regarding the culture shock they have encountered and culture beliefs they held. The author concluded with discussed the findings in relation to traditional Chinese culture, and implies ways where higher education institutions could better serve Chinese international students.

\section{DISCUSSION AND CONCLUSIONS}

A pattern observed across the studies is that, in spite of Chinese international students' status of being a racially minoritized population, none of the articles explicitly discuss the issues of race and racism. Instead, cultural differences are blamed for almost all their negative experiences (e.g., Hanassab, 2006; Lee \& Rice, 2007; Spencer-Rodgers \& McGovern, 2002; K. Wang et al., 2012; Yeh \& Inose, 2003). To be specific, researchers have found that compared with white international students (or international students from Europe) studying in America higher education institutes, international students of color tend to have more acculturative stress (Yeh \& Inose, 2003) and higher chance of receiving discrimination (Hanassab, 2006; Lee \& Rice, 2007; Spencer-Rodgers \& McGovern, 2002). However, rather than building on the findings to unpack more complex issues such as White Supremacy and Whiteness as Property (Harris, 1993), no discussions about race were carried out in these studies. Instead, researchers related such unpleasant experiences to cultural diversity (Hanassab, 2006), intercultural communication barriers (Spencer-Rodgers \& McGovern, 2002), cultural differences (Lee \& Rice, 2007), and cultural distance (Yeh \& Inose, 2003). As Liu (2009) summarized, "[b]ecause of the large cultural differences between long-isolated China and the Western world, Chinese students can face severe cultural shocks upon landing in the U.S." (p. 69-70); it is such cultural shocks that are responsible for the challenges they encounter in the host country.

In the process, a color-blind strategy has been adopted, with culture being overly blamed and race becoming a taboo, ignored as if it does not exist in American society. Color blindness represents a sociology ideology, 
according to which people are viewed based on their characteristics other than race. Despite its face value of being beneficial in promoting racial equality by avoiding overt conversations on race and racism, color-blind racism in reality serves as a new racial ideology since "the mechanisms and practices for keeping blacks and other racial minorities 'at the bottom of the well' changed" (Bonilla-Silva, 2010, p. 2-3). Avoiding the discussions on race by no means help eradicate racism (Bonilla-Silva, 2002, 2010); instead, it reinforces White privilege by denying the unique racialized challenges facing people of color (Williams, 2011), and suppressing their narratives of oppression (Bostick, 2016).

In the case of Chinese international students, the challenges participants are faced with in fitting into the new English-speaking academic environment was interpreted as due to their traditional cultural values, which prompted them to stay with other Chinese international students (M. Wang, 2016), to remain modest and quiet (Jiang, 2014), and to learn by rote (Cheng \& Erben, 2012) rather than interact with native speakers, leaving no space for further investigation and discussions on possible racial segregation between local White college students and international students of color. Furthermore, even when multiple participants directly mentioned issues in relation to race and racism during interviews such as "I saw huge division among different groups (racial, religious, ethnic etc.)" and "[ $\mathrm{t}] \mathrm{he}$ cultural diversity in Los Angeles still coexists with racial stereotypes" (Hanassab, 2006, p. 167), the study still concluded without explicitly addressing race, but instead discussing the importance of cultural diversity on campus and the urge to reduce cultural stereotypes toward international students. Due to color-blind racism, culture is unfairly over-blamed, while deeper discussions on race and power remain absent in research on international students of color.

In contrast, topics around race often show up in immigrant-related studies. For example, through her interviews with 95 multi-generational Asian American participants, Mia Tuan (1998) discussed participants' confronting statuses of simultaneously being Model Minority (or honorary Whites) and forever foreigners in American society. Lee (2005) sharply pointed out that despite their honorary status as the Model Minority, Asian Americans were never treated equally as Whites. Drawing upon careful examination of one-century-long historical events, Takaki (1998) further inferred that such co-existing statuses of Model Minority and forever foreigners of Asian Americans were closely related to the concepts of 
Whiteness as Property (Harris, 1993) and Interest Convergence (Bell, 1980; Delgado \& Stefancic, 2012), both of which served as controlling tools for White power.

While it has been emphasized multiple times in this review that international students are fundamentally different from immigrants, they are also closely interconnected since the "discrimination received by international students is partially related to hostility towards immigrants" (Spencer-Rodgers \& McGovern, 2002, p. 614). This is mainly because "most non-Asians cannot distinguish between Asian ethnics and immigrants; their destinies, for better or worse, are inexorably linked" (Tuan, 1998, p. 147). In other word, although international students of color could be from countries such as China, India, and Korea where racial diversity is not as intense as that of American society, once they travel overseas and enter the U.S. for overseas studies, they are automatically involved into the complex racial structure of the host country.

Yet, given the color-blind lenses through which research on international students have been conducted, it seems that Chinese international students, in spite of their status of being a racially minoritized population in the U.S. just like their immigrant counterparts, are placed in an invisible third place, completely outside the discussion of race and racism in American society. Given that the cultural differences between Eastern and Western societies are here to stay, simply adopting a color-blind strategy to avoid conversations on race and blaming cultural differences for everything is going to perpetuate rather than alleviate the challenges international students of color face during their overseas academic experiences. It is thus important for future research to go beyond color-blind racism, and initiate deeper conversations on the role of race and racism in international student experiences so as to address their challenges from the root cause.

\section{IMPLICATIONS}

With the increasing number of Chinese international students studying in the U.S. each year, and considering the differences between international students and immigrants, it is important to systematically examine this population. This landscape literature review focuses on what research in the 21 st century says about Chinese international students' experiences in American higher education institutes. In answering the two research questions raised earlier, it presents a synthesis of research design, 
underlying assumption, and findings within studies, and discusses patterns identified regarding colorblind racism across studies.

The findings of the literature review have shed lights on future research on Chinese international students mainly in three ways. Firstly, while the vast majority of the studies reviewed identified some kind of challenges Chinese international students experience in their overseas academic experiences, few studies conducted in-depth analysis of the relationship between such challenges and race; instead, culture was unfairly blamed for all these negative experiences. This has betrayed a colorblind racism ideology, which denies the unique challenges Chinese international students face as a racially minoritized group in American society, and undermines the possibility to better understand and support them by addressing those challenges from their root causes. Future research on this topic should conduct further discussions on race and racism, unpack Chinese international students' experiences through a Critical Race Theory lens, and explore how universities could better include and address the needs of international students of color. Secondly, given the many distinctions between international student and immigrant populations, an internationalstudent-oriented theoretical framework should be developed and adopted by future research on Chinese international students, so as to replace the currently dominant frameworks targeting immigrants. Last but not least, considering the fact that Chinese international students represent a heterogeneous group, future research could be conducted to compare the experiences of Chinese international students from different regions (i.e., Hong Kong, Mainland China, and Taiwan) or with different educational backgrounds (i.e., coming directly from Chinese high schools, and having attended high schools or community colleges in the US).

\section{REFERENCES}

Association of International Educators. (2016). NAFSA International Student Economic Value Tool.

Retrieved from http://www.nafsa.org/Policy_and_Advocacy/Policy_Resources/Policy_Trends and_Data/NAFSA_International_Student_Economic_Value_Tool/

Ball, S. J. (1993). Education markets, choice and social class: the market as a class strategy in the UK and the USA. British journal of sociology of education, 14(1), 3-19.

Ball, S. J. (2003). Class strategies and the education market: The middle classes and social advantage. Routledge. 
Batterton, J., \& Horner, S. L. (2016). Contextual Identities: Ethnic and National Identities of International and American Students. Journal of Studies in International Education, 20(5), 472-487.

Bell Jr, D. A. (1980). Brown v. Board of Education and the interest-convergence dilemma. Harvard Law Review, 518-533.

Berry, J. W. (1997). Immigration, acculturation, and adaptation. Applied psychology, 46(1), 5-34.

Bonilla-Silva, E. (2002). The linguistics of color blind racism: How to talk nasty about blacks without sounding "racist". Critical Sociology, 28(1-2), 41-64.

Bonilla-Silva, E. (2010). Racism without racists: Color-blind racism and the persistence of racial inequality in the United States. Rowman \& Littlefield.

Bostick, D. (2016). How Colorblindness is Actually Racist. Retrieved from: http://www.huffingtonpost.com/dani-bostick/how-colorblindness-isact_b_10886176.html

Brown, P. (1990). The 'third wave': Education and the ideology of parentocracy. British journal of sociology of education, 11(1), 65-86.

Brown, P. (1995). Cultural capital and social exclusion: some observations on recent trends in education, employment and the labour market. Work, Employment \& Society, 9(1), 29-51.

Canagarajah, A. S. (1999). Interrogating the "native speaker fallacy": Non-linguistic roots, non-pedagogical results. In G. Braine (Ed.), Non-native Educators in English Language Teaching (p. 77-92). Taylor and Francis.

Center for Immigrant Studies. (2011). Immigrants in the United States: A Profile of America's Foreign-Born Population. Retrieved from: http://cis.org/node/3876

Cheng, R., \& Erben, A. (2011). Language anxiety: Experiences of Chinese graduate students at US higher institutions. Journal of Studies in International Education, 16(5), 477-497.

Creswell, J. W., \& Miller, D. L. (2000). Determining validity in qualitative inquiry. Theory into practice, 39(3), 124-130.

Delgado, R., \& Stefancic, J. (2012). Critical race theory: An introduction. NYU Press.

Fraiberg, S., \& Cui, X. (2016). Weaving Relationship Webs: Tracing how IMing Practices Mediate the Trajectories of Chinese International Students. Computers and Composition, 39(1), 83-103.

García, E. E. (2001). Student cultural diversity: understanding and meeting the challenge. Boston: Houghton Mifflin.

Hanassab, S. (2006). Diversity, international students, and perceived discrimination: Implications for educators and counselors. Journal of Studies in International Education, 10(2), 157-172.

Harris, C. I. (1993). Whiteness as property. Harvard Law Review, 1707-1791.

Institute of International Education. (2009). "All Places of Origin of International Students, Selected Years: 1949/50-1999/00." Open Doors Report on International Educational Exchange. Retrieved from http://www.iie.org/Research-and-Publications/Open-Doors/Data/ International-Students/All-Places-of-Origin/1950-2000 
Institute of International Education. (2016a). "International Students by Academic Level, 2014/15 - 2015/16." Open Doors Report on International Educational Exchange. Retrieved from http://www.iie.org/opendoors

Institute of International Education. (2016b). "Top 25 Places of Origin of International Students, 2014/15-2015/16." Open Doors Report on International Educational Exchange. Retrieved from http://www.iie.org/opendoors

Institute of International Education. (2016c). "International Students by Primary Source of Funding, 2015/16." Open Doors Report on International Educational Exchange. Retrieved from http://www.iie.org/opendoors

Jarratt, S. C., Losh, E., \& Puente, D. (2006). Transnational identifications: Biliterate writers in a first-year humanities course. Journal of Second Language Writing, $15(1), 24-48$.

Jenkins, J. (2006). Current perspectives on teaching world Englishes and English as a lingua franca. Tesol Quarterly, 40(1), 157-181.

Jiang, X. (2014). Chinese biology teaching assistants ' perception of their English proficiency: An exploratory case study. The Qualitative Report, 19(21), 1-24.

Kagawa, M., Hune, S., \& Park, J. (2011). Asian American College Students over the Decades: Insights from Studying Asian American First-Year Students from 1971 to 2005 Using Survey Research Data. AAPI Nexus: Policy, Practice and Community, 9(1-2), 119-126.

Krefting, L. (1991). Rigor in qualitative research: The assessment of trustworthiness. American journal of occupational therapy, 45(3), 214-222.

Lee, J. J., \& Rice, C. (2007). Welcome to America? International student perceptions of discrimination. Higher Education, 53(3), 381-409.

Lee, S. J. (2005). Up against whiteness: Race, school, and immigrant youth. Teachers College.

Li, X., \& Chen, W. (2014). Facebook or Renren? A comparative study of social networking site use and social capital among Chinese international students in the United States. Computers in Human Behavior, 35, 116-123.

Lien, P. T. (2010). Making of Asian America: Through Political Participation. Temple University Press.

Lim, D. Y. (2015). Exploring \& Identifying Predictors That Affect Asian American College Students' Sense of Belonging:" How Do I Fit in?" (Unpublished doctoral dissertation). University of Maryland, College Park, MD.

Lin, C. (2006). Culture shock and social support: An investigation of a Chinese student organization on a US campus. Journal of Intercultural Communication Research, 35(2), 117-137.

Liu, M. (2009). Addressing the mental health problems of Chinese international college students in the United States. Advances in Social Work, 10(1), 69-86.

MacDonald, E. (2009). China's Facebook Status: Blocked. Retrieved from: https://web.archive.org/web/20090711081856/http://blogs.abcnews.com:80/the worldnewser/2009/07/chinas-facebook-status-blocked.html 
Mazzarol, T., \& Soutar, G. N. (2002). "Push-pull" factors influencing international student destination choice. International Journal of Educational Management, 16(2), 82-90.

Pan, J. Y., Wong, D. F. K., \& Ye, S. (2013). Post-migration Growth Scale for Chinese international students: Development and validation. Journal of Happiness Studies, 14(6), 1639-1655.

Park, H. Y. (2016). Culture Clash: Korean International Students in an American High School: English Language Only! [Kindle DX Version]. Retrieved from Amazon.com

Park, J., Lin, M., Poon, O., \& Chang, M. (2008). Asian American college student and civic engagement. In P. Ong (Ed.), The state of Asian America: Trajectory of civic and political engagement (pp. 75-98). Los Angeles, CA: LEAP Asian Pacific American Public Policy Institute

Pedersen, P. B. (1991). Counseling international students. The Counseling Psychologist, $19,10-58$.

Phinney, J. S. (1990). Ethnic identity in adolescents and adults: review of research. Psychological bulletin, 108(3), 499.

Phinney, J. S. (1996). When we talk about American ethnic groups, what do we mean? American Psychologist, 51, 918-927.

Ramazanoglu, C. (1992). On feminist methodology: male reason versus female empowerment. Sociology, 26(2), 207-212.

Sandhu, D. S., \& Asrabadi, B. R. (1994). Development of an acculturative stress scale for international students: Preliminary findings. Psychological reports, 75(1), 435-448.

Spencer-Rodgers, J. (2001). Consensual and individual stereotypic beliefs about international students among American host nationals. International Journal of Intercultural Relations, 25(6), 639-657.

Spencer-Rodgers, J., \& McGovern, T. (2002). Attitudes toward the culturally different: The role of intercultural communication barriers, affective responses, consensual stereotypes, and perceived threat. International Journal of Intercultural Relations, 26(6), 609-631.

Takaki, R. (1998). Strangers from a Different Shore: A History of Asian Americans. New York: Little Brown.

The World Bank. (2016). GDP of China 1961-2015. Retrieved from: http://data.worldbank.org/indicator/NY.GDP.MKTP.CD?end=2015\&locations $=\mathrm{CN} \&$ start $=1961 \&$ view $=$ chart

Tuan, M. (1998). Forever foreigners or honorary whites?: the Asian ethnic experience today. Rutgers University Press.

Wang, K. T., Heppner, P. P., Fu, C. C., Zhao, R., Li, F., \& Chuang, C. C. (2012). Profiles of acculturative adjustment patterns among Chinese international students. Journal of Counseling Psychology, 59(3), 424-436.

Wang, M. (2016). The Impact of Cultural Values on Chinese Students in American Higher Education. The Qualitative Report, 21(4), 611-628.

Wang, W-H. (2009) Chinese International Students' Cross-Cultural Adjustment in the US: the roles of acculturation strategies, self-construals, perceived cultural 
distance, and English self-confidence. Dissertation, University of Texas at Austin.

Ward, C., \& Rana-Deuba, A. (1999). Acculturation and adaptation revisited. Journal of cross-cultural psychology, 30(4), 422-442.

Westmarland, N. (2001, February). The quantitative/qualitative debate and feminist research: A subjective view of objectivity. In Forum Qualitative Sozialforschung/Forum: Qualitative Social Research (Vol. 2, No. 1). Retrieved from: $\quad$ http://www.qualitative-research.net/index.php/fqs/article/ view/974/2124Similarly

Williams, M. (2011). Colorblind Ideology is a Form of Racism. Retrieved from: https://www.psychologytoday.com/blog/culturally-speaking/201112/ colorblind-ideology-is-form-racism

Xue, M. (2013). Effects of group work on English communicative competence of Chinese international graduates in United States institutions of higher education. The qualitative report, 18(7), 1-19.

Yang, C., Wu, H., Zhu, M., Brian, G., \& Southwell. (2004). Tuning in to fit in? Acculturation and media use among Chinese students in the United States. Asian Journal of Communication, 14(1), 81-94.

Ye, J. (2006a). An examination of acculturative stress, interpersonal social support, and use of online ethnic social groups among Chinese international students. The Howard Journal of Communications, 17(1), 1-20.

Ye, J. (2006b). Traditional and online support networks in the cross-cultural adaptation of Chinese international students in the United States. Journal of Computer-Mediated Communication, 11(3), 863-876.

Yeh, C. J., \& Inose, M. (2003). International students' reported English fluency, social support satisfaction, and social connectedness as predictors of acculturative stress. Counselling Psychology Quarterly, 16(1), 15-28.

QIANQIAN ZHANG-WU is a PhD candidate in the Department of Curriculum \& Instruction at the Lynch School of Education, Boston College. Her major research interests lie in the area of bilingualism, bilingual education, higher education research and multiculturalism. Email: qianqian.zhang@bc.edu

Manuscript submitted: January 27, 2017

Manuscript revised: August 4, 2017 Accepted for publication: September 1, 2017 